\title{
Article
}

\section{The influence of randomly allocated group membership when developing student task work and team work capabilities}

Mcclelland, Giles Peter

Available at http://clok.uclan.ac.uk/12632/

Mcclelland, Giles Peter ORCID: 0000-0002-6755-8311 (2012) The influence of randomly allocated group membership when developing student task work and team work capabilities. Journal of Further and Higher Education, 36 (3). pp. 351-369. ISSN 0309-877X

It is advisable to refer to the publisher's version if you intend to cite from the work. http://dx.doi.org/10.1080/0309877X.2011.632818

For more information about UCLan's research in this area go to http://www.uclan.ac.uk/researchgroups/ and search for <name of research Group>.

For information about Research generally at UCLan please go to http://www.uclan.ac.uk/research/

All outputs in CLoK are protected by Intellectual Property Rights law, including Copyright law. Copyright, IPR and Moral Rights for the works on this site are retained by the individual authors and/or other copyright owners. Terms and conditions for use of this material are defined in the policies page.

\section{CLoK}

Central Lancashire online Knowledge www.clok.uclan.ac.uk

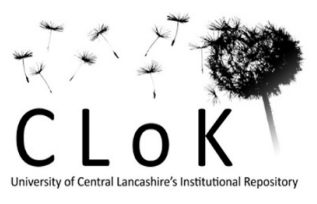


This article was downloaded by: [University of Central Lancashire]

On: 10 December 2012, At: 07:13

Publisher: Routledge

Informa Ltd Registered in England and Wales Registered Number: 1072954 Registered

office: Mortimer House, 37-41 Mortimer Street, London W1T 3J H, UK

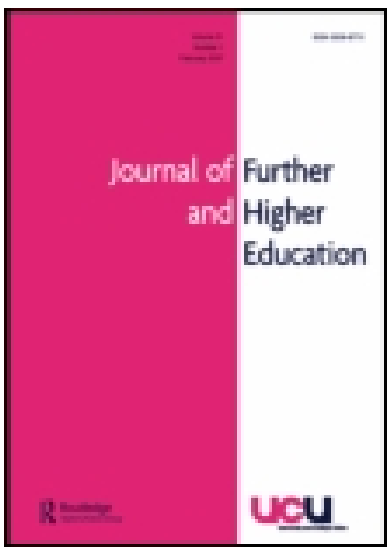

\title{
J ournal of Further and Higher Education
}

Publication details, including instructions for authors and subscription information:

http:// www.tandfonline.com/loi/ cjfh20

\section{The influence of randomly allocated group membership when developing student task work and team work capabilities}

\author{
Giles Peter McClelland ${ }^{a}$ \\ a University of Central Lancashire, Lancashire Business School, \\ Preston, UK \\ Version of record first published: 22 Mar 2012.
}

To cite this article: Giles Peter McClelland (2012): The influence of randomly allocated group membership when developing student task work and team work capabilities, J ournal of Further and Higher Education, 36:3, 351-369

To link to this article: http:// dx. doi.org/ 10.1080/ 0309877X. 2011.632818

\section{PLEASE SCROLL DOWN FOR ARTICLE}

Full terms and conditions of use: http://www.tandfonline.com/page/terms-andconditions

This article may be used for research, teaching, and private study purposes. Any substantial or systematic reproduction, redistribution, reselling, loan, sub-licensing, systematic supply, or distribution in any form to anyone is expressly forbidden.

The publisher does not give any warranty express or implied or make any representation that the contents will be complete or accurate or up to date. The accuracy of any instructions, formulae, and drug doses should be independently verified with primary sources. The publisher shall not be liable for any loss, actions, claims, proceedings, demand, or costs or damages whatsoever or howsoever caused arising directly or indirectly in connection with or arising out of the use of this material. 


\title{
The influence of randomly allocated group membership when developing student task work and team work capabilities
}

\author{
Giles Peter McClelland* \\ University of Central Lancashire, Lancashire Business School, Preston, UK \\ (Received 28 July 2010; final version received 12 January 2011)
}

\begin{abstract}
This study explores whether randomly assigning group membership enhances the student learning experience. The paper starts with a critical analysis of the approaches to student learning within higher education and how these approaches conflict with findings from applied psychology on group behaviour. The study adopts a serendipitous qualitative methodology to explore how changes to assessment requirements can result in a more holistic learning experience. The findings suggest that students perceive the adoption of randomly allocated groups as an unnecessary risk to their performance within assessment as opposed to an opportunity to enhance their learning. This raises questions regarding the conflict that can exist within education between assessment and learning. The results suggest students operate in a 'comfort zone', which can be detrimental to their overall learning experience. Getting students to leave the comfort zone is a particularly stressful situation for both student and educator. Once students leave the comfort zone, competencies that have been dormant surface and they are able to utilise and acquire a wider range of skills. Leaving the comfort zone also results in the creation of a critical incident, which can assist the student in developing their reflective capabilities. The results suggest that randomly allocated groups enhance both an individual's task capabilities and their teamwork capabilities. The paper concludes that the findings have significant implications for those involved in the design of assessment. The paper also provides an interesting commentary on the issues educators face when undertaking education research within a higher educational context.
\end{abstract}

Keywords: group work; team work; holistic learning; critical incident technique; qualitative research; random allocation

\section{Introduction}

The purpose of this research is to identify whether randomly assigning group membership enhances the student learning experience for final-year business students. It is proposed that randomly assigning groups will more accurately simulate the conditions third-year undergraduate students will be

\footnotetext{
*Email: gpmcclelland@uclan.ac.uk 
exposed to when they enter the work environment. Simulating the conditions of the working environment has long since been a recognised problem in teaching Business and Management students (Stephenson and Weil 1992; Mintzberg 1975, 2003). In particular, those with minimal exposure to the work environment find it difficult to contextualise classroom taught theories of individual and group behaviour to the workplace and the students' own specific context.

The research has been defined as a serendipitous study as the decision was made by the author to postpone the initial research at an early stage as a result of significant tensions between the cohort and the module leader who was also undertaking the research. This tension centred on the decision to randomise group selection within a summative assessment. This will be reflected upon later. However, the conditions of the research study continued even though the initial research design was postponed. By creating conflict, though, the study had inadvertently created a critical incident, which is best defined as an emotionally rich event that accelerates learning within those who directly participate in the event. As a research technique, critical incidents have been utilised by Chell (Chell and Pittaway 1998; Chell 2004) largely in relation to the understanding of behaviours and motivations of small business owners. It allows interviewees to reflect on critical experiences that fundamentally result in greater understanding of the self or perception adjustments (Chell and Pittaway 1998). The outcomes that followed the tensions resulted in the researcher believing it was important to capture the findings and write up the experience. However, because the research design was terminated at an early stage, the researcher was unable to capture some of the original objectives of the study; in particular, the opportunity to capture timely data of an empirical nature on students' group development and experiences. Nonetheless, the researcher realised that the original ideas of the experiment were producing some powerful and enriched learning within the student group. An inductive approach was therefore adopted to explore these results and try to make sense of the changes in student learning through causal chain analysis. The term serendipity has been used within research to describe both outputs of research and also approaches to research. Robson (1998), for example, refers to the 'serendipity factor' when describing how significant research findings can come about by chance or accident, namely, when a researcher stumbles across a fortunate discovery within their field. Moses and Knutsen (2007) refer to serendipitous approaches as a more planned research approach in which the researcher sorts through empirical detail to follow a causal chain backwards from an observation of phenomena to determine the most probable cause. In empirical research serendipity is often used to describe the need for a researcher to adapt their research approaches when faced with changes within the context of the study that offer opportunity for greater insight (Holman et al. 2010). Within organisational studies, it has long been acknowledged that the 
researcher must be willing to adjust their research design and also to monitor the environment in which the research is taking place for potential chance opportunities that may arise. Evans (1975) recognised that, in field research, it is very difficult to obtain the controlled conditions required for experimental research. To overcome this limitation when faced with unplanned situations that are somewhat out of the control of a research study, the researcher should demonstrate adaptive capabilities, show a willingness to adjust their research approaches and be well versed in applying different research methods to enable the effective capture of unfolding phenomena. This suggests that serendipitous research occurs when a researcher is able to adapt their approaches and demonstrate creativity in their application of research approaches; it is also an ability to be observant of and reactive to events that may either restrict the research opportunities available to them or create new opportunities to undertake additional research.

Specifically, this research will analyse the effects of randomised selection in group situations on student learning. In analysing these effects, the researcher will adopt a holistic definition of learning (Laird 1985). The basic premise of this approach is that the human personality consists of many elements - 'the intellect, emotions, the body impulse (or desire), intuition and imagination' (121) - that all require activation if the outcomes of learning are to be deeply engrained. Laird identifies that the learner is a complex individual and all the multi-facets (intellect, emotion, intuition, imagination and spirituality) of their being need to be engaged in the learning process. Through tutoring the research sample for two years the researcher intuitively felt that the many facets of the students' personalities were not being fully activated by the education process. The students approaching the end of their education with demanding workloads had become strategic learners. They had now become focused on understanding what they needed to know for assessment at the expense of a more holistic learning experience.

There are two major motivating factors for this study. First, is the opportunity to study how changes to assessment requirements can result in a greater, more enriched student experience. Second, the conflicting results of prior studies within the area (discussed below) tend to suggest a need for further research. The rationale for the study is that, although group work is widely adopted in business schools, the optimum way to structure these activities to result in holistic individual learning is relatively unknown (Schullery and Schullery 2006).

\section{The research setting}

The module in which this research project was undertaken, 'Managerial Decision Making', is a compulsory 30-credit level-6 module delivered on a $\mathrm{BSc}$ (Hons) Business and Management degree within a UK university that the author was previously employed at. The module is unique in its delivery 
of decision making as its focus is not on business decision modelling, which is the common approach across operations and management science-focused degree programmes, but on the human decision-making process. In particular, its focus is more towards how human decision making can deviate from the rational, quantitative and systematic modes studied in more traditional decision-making programmes. The objective of the module is to enable students to understand the variables and contexts that can affect decision making within the workplace and society in general. By enabling the students to recognise the many facets of human decision making, hopefully they will be able to overcome some of the bias that can distort human decision making. In line with the principles of holistic learning, the objective therefore is to not only produce scholars capable of achieving high academic standards but also more capable and well-rounded practitioners.

\section{Learning to be effective in an organisational context}

The module has five learning outcomes, which are assessed using the following assessment strategies: a large group case study, an individual reflection, an individual essay and an examination. Learning outcome 4 focuses on students being able to demonstrate a knowledge of the limitations inherent in and the problems that can arise from group decision making and suggests measures that can be implemented to improve the effectiveness of group decision making. This particular learning outcome is one I felt students had struggled to demonstrate. Although a discussion of the effectiveness of learning outcomes is outside the remit of this paper, the author recognises that effective learning is grounded in experience and critical reflectivity (Marsick and Watkins 2001) and, as such, when there is an opportunity to simulate or experience firsthand the phenomena being studied the curriculum should be designed to take advantage of this.

Business and Management university programmes have long been criticised for their inability to simulate the conditions that lead to effective learning (Mintzberg 1975, 2003; Stephenson and Weil 1992; Bruch and Ghoshal 2004). Mintzberg $(1975,61)$ specifically stressed the limitations of teaching management in a traditional learning environment,

Management schools will begin the serious training of managers when skill training takes a serious place next to cognitive learning. Cognitive learning is detached and informational, like reading a book or listening to a lecture. No doubt much important cognitive material must be assimilated by the manager to-be. But cognitive learning no more makes a manager than it does a swimmer. The latter will drown the first time she jumps into the water if her coach never takes her out of the lecture hall, gets her wet, and gives her feedback on her performance.Mintzberg (1975), early on in his own career, identified that the limitation of management training within the classroom was its focus on teaching of hard, functional capabilities at the neglect of what are commonly 
referred to as 'soft skills', such as dealing with complexity, ambiguity and uncertainty, communicating and working with others and accepting responsibility. In particular, he recognised the difficulties that accrue when practitioner learning and practitioner actions are undertaken in separate contexts during separate time periods. Bruch and Ghoshal (2004) argue that the key skills gap demonstrated by practitioners lies in not knowing what should be done but an ability to take meaningful action. In essence, some managers struggle to put their education and learning into practice. Stephenson and Weil (1992) argued that academic management development programmes portrayed management as a series of functional capabilities that teach students to undertake processes such as the design of a marketing strategy or an HRM policy. This approach teaches functional familiarity at the expense of organisational complexity by dividing the development from implementation. Arguably, contemporary managers are spending more of their time in situations of unfamiliarity than the norms in which educators prepare them for. This has perhaps supported a significant reduction in the confidence in higher education to produce a graduate labour market capable of meeting the needs of employers (Elias and Purcell 2004). Therefore it can be argued that more than ever there is a need to actually remove students from situations in which they are comfortable and create conditions that are capable of slightly unnerving them.

\section{Team-based learning}

One of the methods of overcoming the aforementioned limitations has been the wide adoption of group work as a means to more accurately simulate the conditions of contemporary work environments. Tutors usually have a two-track objective for group-based learning: the acquirement and mastery of subject specific knowledge and the development of group work skills (Schullery and Schullery 2006). Learning to work in conditions of interdependence and collaboration is deemed as one of the most important skills a person can develop to positively influence their employability and ongoing career success (Johnson and Johnson 1989, 32). This is largely a result of the wide adoption of teams as the primary method of work design.

To achieve and maintain levels of flexibility, organisations have altered their habitual approach of designing work around individual jobs to designing work around groups and teams (Ilgen 1999). Boxall and Purcell go so far as to describe teams as the 'fundamental building block of the organization' (2003, 1003). As a result of the perceived positive outcomes accrued from team-based approaches within the workplace, business schools have followed suit by increasing the number of group experiences that a student has during their under- and postgraduate education. Chapman and van Auken (2001), in a study of group work within business schools, identified that, on average, students participated in eight different group projects during an undergraduate Business and Management degree. Indeed, the 
author of this paper undertook an informal analysis of the assessment strategy on the BSc(Hons) Business and Management degree at the university in which he was employed at the time of the research study and identified that only four compulsory undergraduate modules did not contain at least one group-based summative assessment. The majority of these modules are followed by the ubiquitous individual reflective assessment in which students reflect upon the group experience. The key question, though, is how effective are these group projects at developing students' team-based abilities whilst facilitating higher-level learning opportunities?

Teams should not be considered as the most effective learning environment for all activities. Although team-based approaches have become a primary component of organisational work design, there are numerous potential liabilities that perhaps need to be considered when analysing the effectiveness of group-based approaches to learning. To summarise, teams can become riddled with internal conflict (Jehn and Mannix 2001), make riskier decisions than individuals (Lamm et al. 1976), stifle independence and adaptability through conformity (Janis 1982), and result in a lack of knowledge sharing (Sniezek et al. 1990). The findings of Sprigg et al. (2000), in a study of the adoption of a team approach to work design, demonstrated that the adoption of team-based approaches for tasks that do not require a team-based approach actually results in increased job strain, decreased well-being and reduced productivity. Therefore it is worth considering whether the mass adoption of team-based learning approaches is having a counterproductive effect on student skill attainment and student experience.

It is not only in the workplace that teams are capable of counterproductive outcomes. Potential problems can be created by free-riding students, grade inflation for weaker students or grade deflation for stronger students, and tutors' inability to be sure that all students have demonstrated the learning outcomes (Chapman et al. 2006). Chapman and van Auken (2001) stress that academics need to make every effort to design group projects that are capable of overcoming the potential pitfalls associated with this particular mode of learning. However, whether academics fully emphasise to the students the requirement for interdependence and member coordination or the making of individual attainment of goals dependent on team functioning and effectiveness is debatable. It is widely recognised in group work literature that for groups to be effective there has to be a significant degree of both task and outcome interdependence (Procter and Currie 2004). Task interdependence is when all group members are required to share tools, information and capabilities for the group to function effectively, and outcome interdependence is when individuals are reliant on the collective rewards based upon collective performance. Van der Vegt et al. (1999) identified that increased outcome interdependence is important as it helps groups work together. However, high outcome interdependence coupled with low task 
interdependence can result in increased stress and reduced effectiveness. Arguably, the typical undergraduate assessment has very low task interdependence and high outcome interdependence. Individual members often carry other members and the majority of the work is often undertaken by the minority despite the outcome being shared by the group. As a student remarked in the interviews undertaken for this research, 'let's face it, none of these tasks require a group; I could just as much do it myself and to be honest that is what I usually do' (Anonymous female $1^{1}$ ).

Therefore, given that the group-based approach is such a popular vehicle of learning within further and higher education, it is important to understand how factors that influence individual learning can be adjusted to maximise the learning opportunity. This, though, is a sensitive area. If the academic directly intervenes in the group learning process, perhaps as a group facilitator, it would be counterproductive to the ethos of groups becoming selfmanaged teams or it could stifle the development of group interdependence. A factor that the academic is able to manipulate, though, is the way group members are selected.

\section{Group selection in student projects}

The allocation of individuals to student work projects is an area that has received a degree of scholarly interest (Mahenthiren and Rouse 2000; Bacon et al. 2001; Connerly and Mael 2001; Blowers 2003; Chapman et al. 2006; Schulery and Schulery 2006). Connerly and Mael (2001) found that the spread between random or instructor-led selection and student selection was even. Blowers (2003) argued that random group selection is more effective for student learning because it more accurately reflects the conditions they will work within following graduation. In contrast, Bacon et al. (2001) believe that random group selection increases the potential risks, leaving the possibility of students operating in functional groups purely to chance. The authors argue that random selection therefore is playing with students' education. For this reason, Bacon et al. (2001) argue that the process is completely unfair on the students. In addition, scholars also put forth the argument that the process results in inferior performance as opposed to when students can select their own group. Although these are valid findings, it is worth considering that Bacon et al. reached this conclusion not from experimental, empirical research but from interviews with MBA graduates asking them to reflect back upon their programme of study. Connerley and Mael (2001), in an empirical study, were only able to find weak correlations between self-selection and student satisfaction. A shared limitation of this study and the Bacon et al. (2001) study is that they both tend to focus their outcome measures on student satisfaction. It is difficult to put forth a substantial argument that positively correlates student satisfaction with heightened learning experiences within group conditions. Certainly there is 
evidence outside of the educational context to suggest that a degree of conflict and intensity within a group context can heighten performance (Conlon and Murnighan 1991; Jehn and Mannix 2001).

Chapman et al. (2006), in a quasi-experimental study of marketing students, found that randomly assigning groups resulted in slightly lower outcome ratings compared to self-selected groups but the results did not show any significant difference. The main limitation of the study is that outcome measures are self-reported and therefore there is no objective measurement of the quality of outputs, such as the students' overall grades. Schullery and Schullery (2006) undertook a quasi-experimental study to identify whether homogenous personality groups performed any differently to heterogeneous personality groups. The study did include some objective outcome measures in the guise of student assessment marks and instructors' perception of group functioning. Their study identified that positive grade outcomes were associated with both group homogeneity and group heterogeneity. Perhaps the greatest limitation of the study's practicality was that the scholars measured homogeneity based on personality through the Myers-Briggs Type Indicator. Although personality variance is deemed an important construct in groups, fundamentally constructing groups based on personality variance is limited in practicality because teams in the work context are more likely to be constructed based on the skills and abilities required for the task not on employees' personalities.

The literature review has identified that team work plays a significant role in student assessment yet the effectiveness of how it is facilitated within business schools is debatable. There is a lack of empirical evidence to support the proposition that variance in group selection significantly influences group and individual performance outcomes and there has been a distinct lack of research that has ultimately focused on the students' overall learning experience in particular, whether or not the student project can be more effectively facilitated to produce greater learning outcomes. Within the wider group literature there is substantial evidence that a degree of psychographic variance in team membership can result in positive outcomes. Similarly, there is also empirical evidence that a degree of tension and conflict can enhance group performance and learning (Janis 1982; Conlon and Murnighan 1991; Jehn and Mannix 2001). There is a requirement therefore to consider whether altering group selection methods can help instigate greater learning opportunities.

\section{The present study}

The rationale for the study is based on the author's observations of tutoring the cohort for the past two years. The author was aware that the opportunity to self-select group membership coupled with experiences early on in their degree had determined friendships, work relationships 
and opinions on others. The author felt this significantly penalised the students' opportunity to acquire the practical and social skills required within the workplace.

The 'Managerial Decision Making' module looked closely at aspects of how group familiarity can lead to in-group bias and out-group stereotyping (Hilton and von Hippel 1996), the ignorance of minority views ( $\mathrm{Ng}$ and van Dyne 2001) and the adoption of minimally acceptable solutions (Hoffman and Maier 1961), all of which can impair group decision making and effectiveness. This context, therefore, presented an excellent opportunity to expose the students firsthand to theories of group effectiveness through randomly assigning group membership whilst perhaps creating an opportunity for them to become aware of how bias was impairing their decision-making objectivity. This, therefore, would result in a more holistic learning experience upon which the students would be able to reflect.

\section{Research methodology}

The previous studies summarised within the literature review that have studied variance in learning outcomes as a result of group membership have largely adopted comparative, quasi-experimental research strategies (Chapman et al. 2006; Schullery and Schullery 2006). The ethical dilemma of undertaking quasi-experimental research in the classroom largely rests on whether it is acceptable to withhold or withdraw something that could benefit a learner in order to prove its effectiveness. This would result in a potentially penalising effect on either the group who had the variable withdrawn or the group who had it available depending on the outcomes of the experiment. A close analysis of the papers that have used quasi-experimental research to study outcome variance in groups shows no real discussion of how they overcame these ethical considerations; thus I will propose a couple and consider the implications of these changes. The first would be to allow the students to choose whether they wanted to be in the control group and to self-select or be in the randomly allocated groups. A potential concern raised by this approach is that the decision to self-select or leave the outcome to the laws of chance would largely be made according to the individual's personality, which would result in variables within the analysis that would be difficult to identify and capture (openness to new ideas, proactivity, extraversion). The second would be to use a formative assessment thereby reducing the risks highlighted by Bacon et al. (2001) associated with random selection and also the risks associated with the consequences of manipulating variables for different groups within quasi-experimental research. This approach was considered; however, in my personal experience of formative assessment I have been unable to get business students to take it seriously, which means the quality of the results obtained is potentially limited. 
It is not only on ethical grounds that the researcher questioned the effectiveness of quasi-experimental research for achieving the goals of the project. The deductive approaches have produced mixed results and what correlations they have identified between group structure and performance outcomes are weak at best. The results suggest that perhaps the outcomes are more subtle than are able to be captured using a traditional crosssectional quantitative study. Also, perhaps the methodological approaches adopted by the previous researchers, which have largely consisted of postevent interviews, fail to provide the accuracy of information required for such a study. Up to 12 weeks could elapse between interview and critical incidents, which would result in the interviewees finding it difficult to accurately recall the true outcomes of the critical incidents that they are being required to reflect upon. If questionnaires are left until after the assessment has been undertaken, student opinions will be significantly affected by their academic performance in the module. If they have scored poorly, they are more likely to score the learning experience as weak; conversely, if they achieve a good score they are more likely to score the learning experience as high. Although this would not necessarily be the case, this depth of information would be difficult to capture through a questionnaire.

To overcome these limitations, the original plan was to develop a temporal-based research instrument in the form of a diary study. The inclusion of diary methods in a research construct has the advantage of minimising the time that elapses between the experience and its interpretation. This spontaneous capture of rich data can complement the outputs of traditional research approaches (Reis 1994), and it can also reduce the biases introduced by retrospection as a result of elapsed time (Bolger et al. 2003). It was initially decided that all students would keep a diary to capture their experiences of the randomly selected group experience. These diaries would then be analysed by the student to allow them to accurately reflect on the group project as part of their summative assessment. The diaries would then be submitted as an appendix to their individual reflection and at that point the researcher would be able to analyse the data and identify those students the researcher wanted to obtain further data from in the form of semistructured interviews. Despite the planning that had gone into designing a research approach capable of exploring the phenomena in question, the researcher was faced with an obstacle that would in the short term result in the postponement of the research plan.

\section{'The best laid schemes o' mice an' men'}

On the morning of 2 December I had a lecture with the cohort during which I planned to introduce the assessment and the research project, and to randomly appoint students to groups. After introducing the assignment, I made the students aware of my intentions to enhance their 
learning opportunity by assigning them to groups through randomised selection. At this point, the class became disorderly. Students started complaining about the prospect of working with others outside their immediate networks; openly refusing to work with particular colleagues, whilst accusing me of putting their education at risk. I then decided to abort the research. I knew at this stage that I would not be able to get informed consent from the students, and without informed consent the study could not be embarked upon. However, the random assignment of group members was to go ahead. I believed my intentions were just and that the students would receive a more holistic and worthwhile learning experience if I could create a situation which forced them to break from their common routines in order to reveal their cultural beliefs. This approach would thus enrich their learning.

As the assessment progressed I started to realise that some of the students were actually participating in a more effective group project and this was having a positive outcome on their overall learning. Furthermore, the students within the assessment were demonstrating mastery of subjectspecific knowledge and acute group work skills, in some cases to higher standards than had previously been perceived as possible by them. The individual reflections produced by the students also demonstrated a deeper level of understanding that was superior to the usual standard of reflections submitted by third-year undergraduates. In addition, it was evident that for numerous students the morning of 2 December held particular significance and they were reflecting back upon their emotional responses to the situation and using it to put into context their beliefs and behaviours.

\section{Developing a serendipitous study}

Students' reflective papers suggested they had participated in an enriched learning experience. As a researcher, I was drawn towards understanding and exploring the causal chain backwards to understand the most probable cause. Therefore, following the assessment of the work a series of semistructured interviews were quickly organised with students who had found the experience particularly enriching for various reasons. Informed consent was obtained following a clear written briefing detailing the objectives of the research, the requirements and consequences of participation. This included making the students aware that the interviews would be filmed and the filmed interviews may be used to encourage future students to participate in randomly assigned group projects.

The objective of the study was to allow the researcher the opportunity to explore the students' opinions and outcomes as a result of the critical incident. Semi-structured interviews were chosen largely because for areas of applied research in which the subject matter is too complex to 
quantify or the theories are at a stage of insufficient development, interviews offer a more flexible and adaptive instrument to study the phenomenon in question than traditional survey designs (Lee et al. 1999).

\section{Results}

A number of key findings became apparent as a result of the analysis. First, students expressed significant levels of unease at being requested to leave their 'comfort zones', which resulted in perceptions of enhanced risk. Second, within the randomly allocated groups the surfacing of new skills was apparent within students which mediated enhanced self-efficacy. Third, a number of students believed they expended greater levels of effort as a result of working with new individuals, which directly contributed to individual judgements of enhanced learning. Finally, students felt the experience enhanced their reflective capabilities as a result of having a critical incident to focus their reflection upon. These points will now be explored in detail.

\section{Learning in the comfort zone}

The findings indicate that students previously believed that learning was more effective when students were in a comfort zone. This suggests that the students' perceptions of effective learning differed to the views of scholars who propose that the most effective learning takes place in conditions that result in a degree of the unknown (Laird 1985; Marsick and Watkins 2001). The student learning comfort zone comprises the degree of control they have over whom they interact and work with, when and where the learning takes place, adhering to what they perceive is their 'normal role' within group work and a focus on learning the skills required for successful performance within assessment. Arguably, this comfort zone is unrealistic in relation to contemporary working environments. Students demonstrated significant unease when asked to leave the comfort zone; they also stated that this was the first time they had been requested to work outside their immediate peer groups at Levels 5 and 6: 'In my usual group I know what my role is and then I know how to work with people... . I just did not like the idea of working with people I did not usually talk to' (Anonymous female 1).

Students met requests to leave their comfort zone with hostility as they believed their usual performance outcomes in regards to assessment were being placed at risk. The students could not understand that even the risk of poor performance could be offset by participation in an enhanced learning experience that would give them greater opportunity to explore varying factors within their analysis. It is interesting at this stage to consider that the undergraduates who participated in this study believed that assessment and learning are one and the same thing, rather than assessment being only an 
indicator of learning. The students focus on assessment, and it is worth considering that this may detract from actual learning:

I did not like the idea because we got to the point where we knew everything we were good at and how we were going to operate ... if it hadn't have worked out it would have affected my overall grade. (Anonymous male 2)

From that session when there were a lot of arguments ... they felt one mark could change their whole degree classification. So they think they would rather go with who they know. (Anonymous female 3)

\section{Leaving the comfort zone}

The study identified that when students actually left their comfort zone their individual performance was significantly enhanced. This surfaced through the development of new skills, the adoption of preferred roles, the opportunity to step out of the shadows and the need to take greater overall ownership for the task outcomes. There was also evidence that the attributes of effective team work were enhanced, such as students demonstrating greater levels of back-up behaviour and mutual performance monitoring:

It helped that because we didn't know everybody no one wanted to drag the team down. Everybody was willing to put that little bit extra effort in. Whereas if you work with someone you know, you are more likely to sit back slightly. (Anonymous male 4)

I had to do it as otherwise I wouldn't be pulling my weight in the group work and that would not be fair on others. Whereas when you are more comfortable with others they do not mind if you slack off a bit. (Anonymous female 5)

Some high-performing members of the cohort who usually feel obliged to work within their social group actually got the opportunity to work with other high-performing colleagues, which resulted in them doing less work but contributing in areas they felt were more personally rewarding and less frustrating: 'Martin was the person in the group that I usually am. That was good because I quite like to look at whether the work is done and correct as opposed to doing all the work, which is what I usually do' (Anonymous female 6).

Not all the teams performed well. High-performing students often found themselves in groups who did not share their work ethic. This caused them frustrations early on in the project. However, the barriers to high performance resulted in them having to work harder and to reconfigure their usual work role to the needs of the new group. The result of this was leadership qualities surfacing in individuals who had not had that opportunity before:

I realised I was going to have to make this work. (Anonymous female 7) 
Maybe I did perform better in the groups I was set because it was on me to do it. I could not sit back. I sort of had to take charge. (Anonymous male 8)

I had to take on more responsibility because they were not prepared to make arrangements to get the work. It is something I had to adopt. (Anonymous female 9)

Interestingly, students who usually played a less significant role in groups identified that working in randomly allocated groups resulted in them having to adopt a more active role within group work, which resulted in them experiencing positive personal outcomes: 'They expected me to do more work. Not that I do not usually do work, it is just I usually sit back. . . . I felt quite proud of myself... . I felt good that I had done my own work instead of relying on other people to help me' (Anonymous female 10).

One particular student who had worked with his high-performing friends throughout his education expressed that this opportunity allowed him to play a more active role instead of leaving the majority of the work to his friends: 'I got the chance to perform better ... in this you had to step up and improve yourself' (Anonymous male 11).

\section{Enhanced reflective capabilities}

Being placed into randomly selected groups and thus removed from their comfort zone gave the students the opportunity to produce better quality reflections because the experience prompted new insights (Laird 1985). As one student remarked, 'I was able to look at things from different angles' (Anonymous female 12). This enhanced opportunity to reflect is something that can only be created if students are encouraged to break from their commonplace routines and be exposed to new experiences. By creating the need to develop as a team for the delivery of an outcome, students were able to contextualise some of the theories of group skills and group development to a standard some had not been capable of undertaking prior to this exercise. This provides further evidence that effective learning is both cognitive and experience based (Mintzberg 1975).

\section{Areas for future consideration}

The study has raised a number of key areas and considerations for educators and pedagogic scholars. First and foremost, the study supports the argument by Blowers (2003) that random group selection provides a more enhanced learning context for undergraduate students. The results suggest that randomised group selection can enhance both task work capabilities and team work capabilities in undergraduate students. Thus, the study provides a qualitative argument that directly contradicts the arguments put forward by Bacon et al. (2001). 
The students who participated in the study concluded in the interviews that they did not understand why random group selection is not utilised more within undergraduate assessment. The author tends to share the same puzzlement. Further research perhaps could investigate the barriers to greater utilisation of randomised groups in assessment strategies and whether these barriers differ across different disciplines. Social psychological perspectives of behaviour propose that humans naturally seek out culturally homogenous groups (Tajfel 1982), which suggests that the situations described in this paper may not be just be isolated in one discipline.

A further issue is that the findings suggest that students are being educated within their boundaries of comfort. Theories suggest that learning is more enhanced when the multi-facets of intelligence (cognitive, emotional, spiritual) are activated by the learning experience (Laird 1985). To facilitate this, learners must be encouraged and supported to break from commonplace routines in order to understand the cultural contexts that frame their understandings. Likewise, organisations are spending less time in periods of routine stability (Stephenson and Weil 1992). If we are allowing students to stay within their comfort zone, arguably we are not providing an adequate learning experience that simulates the environmental conditions of the real world. They are thus illprepared for the situations they will find themselves in when they are entrenched in the working environment. Students in this project, despite their initial misgivings, expressed gratitude at being given the opportunity to participate in a holistic learning activity. As educators, we need to ensure more of these opportunities are provided within our programmes. An area for future research is to understand how students can be challenged but feel their degree classification is not being placed at risk. This may require lecturers to reflect upon their own comfort zones and whether their boundaries should be breached once in a while.

Finally, students need to understand the ethos of holistic learning. Students sometimes perceive that the assessment is the process and outcome of learning. This is not the case. Assessment is only a single component of learning. It is an opportunity for the student to demonstrate that they have the potential to consider different behaviours and viewpoints. However, deep learning comes not from an ability to demonstrate but from sustained change within the learner. The focus on assessment is leading to a preoccupation with degree classification within higher education. This has positive implications, as students should aspire to obtain the best possible grades. However, it also has the potential to be a destructive force, capable of driving the wrong behaviours by lecturers and students alike whilst not facilitating an enhanced learning experience. A key area for consideration is whether the focus on a narrow set of performance outcomes restricts educators from delivering holistic learning opportunities. 


\section{Implications for educators}

I will conclude this paper with a consideration of how randomly allocated group assessments can be implemented more effectively in course delivery and assessment. First and foremost, educators need to be fully versed on the true benefits and risks associated with group work and this needs to be articulated effectively to students so that they can understand both the task and team work capabilities they need to develop to become effective learners and practitioners. Hopefully this paper will raise a greater awareness in educators of the characteristics of group work.

Assessment should be designed that is capable of requiring both high levels of task and outcome interdependence from students. Arguably, one without the other results in a potentially negative learning experience, which could result in counterproductive implications for the students' learning. In particular, for group assessments that do not require high levels of task interdependence, consideration should be given to whether individual as opposed to group-based assessment would be more beneficial. If the assessment is not developing team work capabilities effectively, then whether group-based assessment is the most effective assessment strategy needs to be considered. This implication is drawn from research findings in work design, which proves that putting people in teams when there is no need to work in teams is actually counterproductive to both individual-, group- and organisational-level outcomes (Sprigg et al. 2000). External moderators, course leaders and module leaders need to examine the effectiveness of group-based assessment strategies and consider whether they are capable of developing both task work and team work capabilities. It is proposed that degree programmes should utilise both randomly allocated and self-select group membership for teambased assessment. Doing so will give students the opportunity to truly explore their own capabilities within teams and the ways in which they can overcome some of the barriers to high performance associated with team work. Ideally, this approach should be implemented from the start of their undergraduate degree programme and continued throughout their studies. Finally, if I adopt the same principles and learning strategy in future modules, I will utilise the findings from this research to first assist students in understanding the benefits of randomly allocated groups. Doing so I hope will overcome some of the resistance I experienced in this example. In analysing the transcripts of the video-recorded interviews, a small film was created. It is proposed this is shown to students next year to help alleviate some of the anxiety associated with leaving their comfort zone. Technological innovations are allowing researchers to disseminate their findings more effectively to multiple beneficiary groups, thus increasing the impact of research programmes. This approach could assist future learning and development within higher and further education. 


\section{Note}

1. All interviews were conducted and video-recorded in 2010 by Giles McClelland. For the sake of confidentiality, the names of interviewees are withheld by mutual agreement.

\section{Notes on contributor}

Giles McClelland is a senior lecturer in the Division of Economics and International Business at Lancashire Business School, University of Central Lancashire. He has also worked in both the private and public sector within the fields of project management. Giles' existing research portfolio is based around two areas. First, he has published the results of a large-scale study focusing on the relationship between customer management and business growth in small and medium-sized enterprises (SMEs). The research focused on both the systems and behaviours that assist SMEs to maximise the opportunity for growth. Second, Giles' research is now firmly located within the area of industrial/organisational psychology, particularly the investigation of how teams alter the architecture of their work to achieve mutually beneficial organisational and team-based outcomes. His main focus is on identifying the major contextual factors that enable teams to adjust their immediate environment. Giles also has a keen interest in applying theories of team effectiveness in the classroom to enhance student learning.

\section{References}

Bacon, D.R., K.A. Stewart, and E.S. Anderson. 2001. Methods of assigning players in teams: A review and novel approach. Simulation and Gaming 32, no. 1: 6-17.

Blowers, P. 2003. Using student skill self assessment to get balanced groups for group projects. College Teaching 50, no. 3: 106-10.

Bolger, N., A. Davis, and E. Rafaeli. 2003. Diary methods: Capturing life as it is lived. Annual Review of Psychology 54: 579-616.

Boxall, P., and J. Purcell. 2003. Strategy and human resource management. Basingstoke: Palgrave Macmillan.

Bruch, H., and S. Ghoshal. 2004. Management is the art of doing and getting done. Business Strategy Review 3, no. 15: 4-13.

Chapman, K.J., and S. van Auken. 2001. Creating positive group experiences: An examination of the role of the instructor on students' perceptions of group projects. Journal of Marketing Education 22, no. 2: 117-27.

Chapman, K.J., M. Meuter, D. Toy, and L. Wright. 2006. Can't we pick our own groups? The influence of group selection method on group dynamics and outcomes Journal of Management Education 30, no. 4: 557-69.

Chell, E. 2004. Critical incident technique. In Essential guide to qualitative methods in organisation studies, ed. C. Cassell and G. Symon. London: Sage.

Chell, E., and L. Pittaway. 1998. A study of entrepreneurship in the restaurant and cafe industry: Exploratory work using the critical incident technique as a methodology. International Journal of Hospitality Management 17: 23-32.

Conlon, D.E., and J.K. Murningham. 1991. The dynamics of intense work groups: A study of British string quartets. Administrative Science Quarterly 36: 165-86.

Connerley, M.L., and F.A. Mael. 2001. The importance and invasiveness of student team selection criteria. Journal of Management Education 25, no. 5: 471-94. 
Elias, P., and K. Purcell. 2004. Is mass higher education working? Evidence from the labour market experiences of recent graduates. National Institute Economic Review 90: 60-74.

Evans, M.G. 1975. Opportunistic organizational research: The role of patch-up designs. Academy of Management Journal 18: 98-108.

Hilton, J.L., and W. von Hippel. 1996. Stereotypes. Annual Review of Psychology 47: $237-71$.

Hoffman, L.R., and N.R.F. Maier. 1961. Quality and acceptance of problem solutions by members of homogenous and heterogeneous groups. Journal of Abnormal and Social Psychology 62: 401-7.

Holman, D.J., C.M. Axtell, C.A. Sprigg, P. Totterdell, and T.D. Wall. 2010. The mediating role of job redesign interventions: A serendipitous quasi-experiment. Journal of Organizational Behaviour 31: 84-105.

Ilgen, D.R. 1999. Teams embedded in organizations: Some implications. American Psychologist 54: 129-39.

Janis, I.L. 1982. Groupthink: Psychological studies of policy decisions and fiascos. Boston, MA: Houghton-Mifflin.

Jehn, K.A., and E.A. Mannix. 2001. The dynamic nature of conflict: A longitudinal study of intra-group conflict and group performance. Academy of Management Journal 44, no. 2: 238-51.

Johnson, D.W., and R.T. Johnson. 1989. Social skills for successful group work. Educational Leadership 47, no. 4: 29-33.

Laird, D. 1985. Approaches to training and development. Reading, MA: AddisonWesley.

Lamm, H., D.G Myers, and R. Ochsmann. 1976. On predicting group-induced shift toward risk or caution: A second look at some experiments. Psychologische Beitrage 18: 288-96.

Lee, T.W., T.R. Mitchell, and C.J. Sablynski. 1999. Qualitative Research in Organizational and Vocational Psychology, 1979-1999. Journal of Vocational Behavior 55, no. 2: 161-87.

Mahenthiren, S., and P.J. Rouse. 2000. The impact of group selection on student performance and satisfaction. International Journal of Educational Management 14, no. 6: 255-64.

Marsick, V.J., and K.E. Watkins. 2001. Informal and incidental learning. New Directions for Adult and Continuing Education 89: 25-34.

Mintzberg, H. 1975. The manager's job: Folklore and fact. Harvard Business Review 53, no. 4: 49-61.

Moses, J.W., and T.L. Knutsen. 2007. Ways of knowing. Basingstoke: Palgrave Macmillan.

Ng, K.Y., and L. van Dyne. 2001. Individualism-collectivisim as a boundary condition for effectiveness of minority influence in decision making. Organizational Behaviour and Human Decision Process 84, no. 2: 198-225.

Procter, S., and G. Currie. 2004. Target based team-working: Groups, work and interdependence in the UK Civil Service. Human Relations 57, no. 12: 1547-72.

Reis, H.T. 1994. Domains of experience: Investigating relationship processes from three perspectives. In Theoretical frameworks in personal relationships, ed. R. Erber and R. Gilmore, 87-110. Mahwah, NJ: Erlbaum.

Robson, C. 1998. Real world research. Oxford: Blackwell. 
Schullery, N.M., and S.E. Schullery. 2006. Are heterogeneous or homogeneous groups more beneficial to students? Journal of Management Education 30, no. 4: 542-56.

Sniezek, J., P. Paese, and S. Furiya. 1990. Dynamics of group discussion to consensus judgment: disagreement and overconfidence. Unpublished manuscript, University of Ilinois.

Sprigg, C.A., P.R. Jackson, and S.K. Parker. 2000. Production team-working: The importance of interdependence for employee strain and satisfaction. Human Relations 53: 1519-43.

Springer, S.P., and G. Deutsch. 1989. Left brain, right brain. New York: W.H. Freeman.

Stephenson, J., and S. Weil. 1992. Quality in learning: A capability approach in higher education. London: Kogan Page.

Tajfel, H. 1982. Social psychology of intergroup relations. Annual Review of Psychology 33: 1-39.

Van Der Vegt, G., B. Emans, and E. van de Vliert. 1999. Effects of interdependencies in project teams. Journal of Social Psychology 139, no. 2: 202-14. 